\title{
Reducing inequalities in oral disease
}

\author{
David M. Williams \\ Bart's and The London School of Medicine and Dentistry
}

The World Health Organisation asserts that oral health is a basic human right ${ }^{1}$ yet this a right enjoyed by few. Dental caries is one of the most common chronic diseases worldwide, ${ }^{2}$ leading to millions of lost days of schooling and absenteeism from work; periodontitis is a major cause of tooth loss worldwide; ${ }^{3-5}$ oral cancer is the eighth most common cancer worldwide; ${ }^{6}$ oral infections are a major cause of oral disease; ${ }^{7}$ and cleft palate, with a global incidence ranging from 1 to 4 per 1,000 live births, ${ }^{8}$ is always expensive to treat.

In high-income countries the cost of treating oral diseases often exceeds that for major diseases such as cancer, heart disease, stroke and dementia. This is simply astonishing, given that dental caries is preventable through the use of fluoride and other cost-effective measures. ${ }^{2}$ In low-to-middle income countries oral diseases are a severe and growing public health problem. More worrying still, major inequalities exist both within and between countries in terms of disease severity and prevalence. ${ }^{9}$ Major social gradients exist in the prevalence of oral disease ${ }^{10}$ and, whilst we have been poor in implementing what we know about the prevention of dental caries, periodontal disease, oral cancer and oral infections, arguably a more significant reason for our relative ineffectiveness in reducing the global burden of disease has been our failure to address the social determinants of oral diseases.

\section{WHAT IS TO BE DONE, AND BY WHOM?}

All of the abovementioned issues raise important questions about what is to be done, and by whom? Earlier this year I asked $^{11}$ "what responsibilities do we have as a dental community of researchers, policy makers, educators and clinicians? It is relatively easy, but not enough, to say that we need outstanding fundamental research to improve our basic understanding of the diseases that concern us; that we need to deliver effective, ethical, evidence-based oral health promotion and care; that we need effective prevention as well as more effective treatments; and that we need to establish the kinds of workforce appropriate to a range of global settings. We still have a very long way to go in advocating effectively and implementing the potential improvements in oral health that are known to be achievable. Most importantly, the situation is unlikely to change without a transformation in our priorities for research and practice'. Tackling global oral health inequalities will require creativity, diligence and a strong commitment to partner with the many players involved in global health. ${ }^{12}$ The International Association for Dental Research has responded to the challenge through the Global Oral Heath Inequalities: the Research Agenda (GOHIRA) initiative and is in the process of agreeing the priorities for research that can lead to a reduction in inequalities in oral health within and between countries. It will tackle the social determinants of oral health and thereby improve global oral health and reduce inequalities. This approach has the potential to bring significant, real health benefits to the world's population. It is amazing that decisions about healthcare, including oral healthcare, are still being made without a solid research evidence base. ${ }^{13}$ It is this deficiency that GOHIRA is determined to address.

1. Petersen PE, Kwan S. The 7th WHO Global Conference on Health Promotion towards integration of oral health. Community Dent Health 2010; 27(Suppl 1): 1-11.

2. Pitts N, Amaechi B, Niederman R et al. Global oral heath inequalities: dental caries task group - research agenda. Adv Dent Res 2011; 23: 211-220.

3. Petersen P E, Bourgeois D, Ogawa $\mathrm{H}$ et al. The global burden of oral diseases and risks to oral health. Bulletin WHO 2005; 83: 661-669.

4. Pihlström B L, Michalowicz B S, Johnson N W. Periodontal diseases. Lancet 2005; 366: 1809-1820.

5. Jin L J, Armitage G C, Klinge B et al. Global oral heath inequalities: task group periodontal disease. Adv Dent Res 2011; 23: 221-226.

6. Johnson N W, Warnakulasuriya S, Gupta P C et al. Global inequalities in incidence \& outcomes for oral cancer: causes \& solutions. Adv Dent Res 2011: 23: 237-246.

7. Challacombe S J, Chidzonga M, Glick M et al. Global oral heath inequalities - oral infections: challenges and approaches. Adv Dent Res 2011; 23: 227-236.

8. Mossey P A, Shaw W C, Munger R G et al. Global challenges in the prevention and management of orofacial clefts and potential solutions. Adv Dent Res 2011; 23: 247-258.

9. Marmot M, Bell R. Social determinants and dental health. Adv Dent Res 2011; 23: 201-206.

10. Sheiham A, Alexander D, Cohen L et al. Global oral health inequalities: task group - implementation and delivery of oral health strategies. Adv Dent Res 2011; 23: 259-267.

11. Williams D M. Global oral health inequalities: the research agenda. J Dent Res 2011; 90: 549-551.

12. Garcia I, Tabak L A. Global oral health inequalities: the view from a research funder. Adv Dent Res 2011; 23: 201-210.

13. Pang T, Terry R F, The PLoS Medicine Editors. WHO/PLoS Collection 'No Health Without Research': a call for papers. PLoS Medicine 2011; 8: 1-2.

DOI: $10.1038 /$ sj.bdj.2011.337 